\title{
BMJ Open Environmental tobacco smoke and the risk of eczema symptoms among school children in South Africa: a cross-sectional study
}

\author{
Joyce Shirinde, ${ }^{1}$ Janine Wichmann, ${ }^{2}$ Kuku Voyi ${ }^{2}$
}

To cite: Shirinde J, Wichmann J, Voyi K. Environmental tobacco smoke and the risk of eczema symptoms among school children in South Africa: a cross-sectional study. BMJ Open 2015;5:e008234. doi:10.1136/bmjopen-2015008234

- Prepublication history for this paper is available online. To view these files please visit the journal online (http://dx.doi.org/10.1136/ bmjopen-2015-008234).

Received 18 March 2015 Revised 25 June 2015 Accepted 30 June 2015

CrossMark

\footnotetext{
${ }^{1}$ Department of

Environmental Health,

Tshwane University of

Technology, Pretoria,

South Africa

${ }^{2}$ Health Sciences Faculty, School of Health Systems and Public Health, University of Pretoria, Pretoria,

South Africa
}

Correspondence to Dr Joyce Shirinde; shirindej@tut.ac.za

\section{ABSTRACT}

Objective: The aim of this study was to investigate the association between eczema ever (EE) and current eczema symptoms (ES) in relation to exposure to environmental tobacco smoke (ETS).

Design: A cross-sectional study using the International Study of Asthma and Allergies in Childhood questionnaire.

Setting: 16 schools were randomly selected from two neighbourhoods situated in Ekurhuleni Metropolitan Municipality, Gauteng Province, South Africa.

Participants: From a total population of 3764 school children aged 12-14 years, 3468 completed the questionnaire (92\% response rate). A total of 3424 questionnaires were included in the final data analysis. Primary outcome: The prevalence of EE and current ES was the primary outcome in this study.

Results: Data were analysed using Multilevel Logistic Regression Analysis (MLRA). The likelihood of EE was increased by exposure to ETS at home (OR $1.3095 \%$ $\mathrm{Cl} 1.01$ to 1.67 ) and at school (OR $1.2695 \% \mathrm{Cl} 1.00$ to 1.60). The likelihood of EE was lower for males (OR $0.6695 \% \mathrm{Cl} 0.51$ to 0.84 ). The likelihood of ES was increased by ETS at home (OR $1.9395 \% \mathrm{Cl} 1.43$ to 2.59) and school (1.44 95\% Cl 1.09 to 1.90). The likelihood of ES was again lower for males (OR 0.56 $95 \% \mathrm{Cl} 0.42$ to 0.76 ). Smoking by mother/female guardian increased the likelihood of EE and ES, however, this was not significant in the multivariate analysis.

Conclusions: Symptoms of eczema were positively associated with exposure to ETS at home and school. The results support the hypothesis that ETS is an important factor in understanding the occurrence of eczema.

\section{BACKGROUND}

Eczema (or atopic dermatitis, $\mathrm{AD}$ ) is a chronic, and the most frequent, inflammatory skin disease; it usually develops in childhood and can persist through to adulthood. ${ }^{1}$ It is characterised by dry skin, itchy rash and excoriation, ${ }^{2}{ }^{3}$ and the condition affects
Strengths and limitations of this study

- The use of a validated International Study of Asthma and Allergies in Childhood (ISAAC) questionnaire, which has been used in many studies globally with consistent results.

- Large sample size of over 3000 children.

- The participation rate was high $(92 \%)$.

- The results of the study might be higher than the actual prevalence since they are based on self-reported answers from the questionnaire and no objective measures were taken at the time of data collection.

$15-30 \%$ of children and $2-10 \%$ of adults. ${ }^{3}$ The term eczema describes skin diseases with common clinical characteristics involving a genetically determined skin-barrier defect. Decreased barrier function leads to increased water loss through the outermost layer of the skin, resulting in a decrease in water content of this particular layer of skin, increased permeability to hydrophilic substances, decreased ceramides in the skin and decreased barrier to infectious agents. ${ }^{4}$ Although not life-threatening, the condition may result in secondary infection and damage to the skin. The quality of life for those having the condition, particularly children and their caregivers, may be affected, for example, by lack of sleep and lack of concentration at school as a result of itching at night. ${ }^{5}{ }^{6}$ Families of affected children have an extra financial burden to care for the affected child. ${ }^{78}$ The prevalence of eczema among children is reported to vary in different countries, with some countries experiencing an increase, and others with high prevalence undergoing a decline. ${ }^{9-11}$

In Cape Town Province, South Africa, Zar et $a l^{12}$ reported an increase in the prevalence of eczema from $11.8 \%$ in 1995 to $19.4 \%$ in 2002, from two International Study of 
Asthma and Allergies in Childhood (ISAAC) studies that were questionnaire based and conducted 7 years apart. The reason for the increase in the prevalence of eczema is not clearly understood. The pathogenesis of eczema is complex, involving an interaction between several factors, which may include, among others, genetics, socioeconomic status, lifestyle, diet, meteorological and living conditions at home, and environmental air pollutants, such as type of fuel used for cooking and heating in homes, and traffic-related air pollution and exposure to environmental tobacco smoke (ETS). ${ }^{13-16}$

Tobacco smoke is one of the most common indoor air pollutants. The literature, as early as in the 1970 s, periodically reviewed ETS, or passive smoking and health. ${ }^{17}$ Children usually get exposed to tobacco smoke at home due to parents and other family members smoking, but also during transportation and in areas such as schools and restaurants. ${ }^{18}$ Although ETS has been considered to be a risk factor for eczema, the relationship between the two has not been sufficiently investigated. Studies have reported that smoking by the mother, or her exposure to smoke during pregnancy, may increase the risk of eczema during childhood. ${ }^{19}$

Many studies focusing on eczema have been mainly reported from studies conducted in developed countries; little is known about the strength of such associations in developing countries such as South Africa. The aim of the study was to investigate the association of eczema ever (EE) and current eczema symptoms (ES) with ETS among children attending schools in urban areas of Tembisa and Kempton Park.

\section{METHODS}

Study area

The study was conducted in Tembisa and Kempton Park areas, situated in the northern region of the Ekurhuleni Metropolitan Municipality (EMM), located in the eastern region of Gauteng Province, South Africa. Tembisa is the second largest township in Gauteng Province, with both formal and informal housing; it is home to mainly African ethnic groups. Kempton Park is a suburban area and the residents are predominantly Caucasian; it has only been in recent years, after the 1994 democratic elections, that some, mostly middle income, African ethnic families have moved into the area.

\section{Study design, population and sample selection}

A cross-sectional epidemiological study was conducted between February and June 2012, following the ISAAC Phase I protocol. ${ }^{20}$ The ISAAC was designed as a multicentre study to investigate the epidemiology of asthma, rhinitis and $\mathrm{AD}$ among children, using standardised definitions, thus allowing comparisons worldwide. ${ }^{20} \mathrm{~A}$ list of all schools (primary and secondary) in EMM was provided by the Gauteng Department of Education. All primary schools were excluded and 16 high schools were randomly selected from the list. Each school was contacted and requested to participate in the study. Following the approval of the study by the principal and governing body in each school, all eligible children between the ages of 13 and 14 years and in grade 8 were requested to participate. An appointment was scheduled with the school to deliver the consent forms for the children 2 weeks prior to the study and the children were requested to return them within 3 days. The study population consisted of 3764 children, based on the numbers given by each school prior to data collection. Data were collected using the English versions of ISAAC written and video questionnaires. The questionnaires were completed by the children in the classroom under the supervision of the data collectors, who were specifically trained and briefed to avoid explanations that could interfere in the participant's answers.

\section{Health outcomes}

In this study, we estimated health outcomes on the basis of positive answers from the written ISAAC questionnaire. Answers to written questions were self-reported by children.

1. Have you ever had an itchy rash that was coming and going for the past 6 months? (Yes\No)

2. Have you had this itchy rash at any time in the past 12 months? (Yes $\backslash$ No)

3. Has this itchy rash at any time affected any of the following places: the folds of the elbow, behind the knees, in front of the ankles, under the buttocks, or around the neck, ears, or eyes? (Yes $\backslash$ No)

4. Current ES were defined as those children who, according to the written questionnaire, responded positively to questions 1,2 and 3 .

5. EE: have you ever had eczema? (Yes\No)

\section{Air pollution sources and potential confounding variables}

Air pollution sources included: ETS exposure at home in the past 30 days (yes/no), ETS exposure at school in the past 30 days (yes/no), tobacco smoking by participant (yes/no), mother/father smoking tobacco (yes/no), any other person smoking at home other than participant (yes/no). The following potential confounding variables were included in the study, similar to other ISAAC studies, ${ }^{21}$ age, sex (male/female) and type of house (brick, mud, corrugated iron, combination); the children were asked to select the most frequently used energy source at home: for cooking (electricity, gas, paraffin, open fires) and for heating (electricity, gas, paraffin, open fires). The children were asked about the mode of transport to school (walking, taxi/bus, car, combination of car/taxi or train), the frequency of trucks passing near residences on weekdays (never, seldom, frequently through the day, almost all day). Other variables included in the questionnaire and reported in the descriptive analysis included: period lived in the residential area ( $<6$ months, 6-12 months, 1-2 years, $\geq 3$ years), being born in Tembisa/Kempton Park (yes/no) and availability of running water (yes/no). 


\section{Data management and statistical analysis}

The data were entered into a database set up in Epilnfo V.3.5.3 and Stata V.12 was applied for the data analysis. Prevalence rates for the each health outcome and proportion of risk factors under investigation were calculated by dividing the number of participants who responded affirmatively to a particular question, by the number of questionnaires completed. Observations marked as 'do not know', 'not stated' or 'other responses' were set as missing. This resulted in each question having a slightly different sample size. Crude and adjusted OR and 95\% CI were calculated with Multilevel Logistic Regression Analysis (MLRA) with random effect to estimate the likelihood of having EE and current ES given ETS exposure variable.

The multilevel data included 16 schools within two residential areas (Kempton Park and Tembisa) at level 1. ETS and confounding variables were added in a stepwise manner, starting with the most significant from the univariate analysis. Each time a new potential confounder was added to the model, if the effect estimate between the exposure of interest and respiratory outcome already in the models changed by more than $5 \%$, the additional variable was retained in the final multiple MLRA, otherwise, the variable was removed and a different one was added. $^{22}$ The most parsimonious multiple MLRA models were reported, that is, those with variables having a $\mathrm{p}$ value $<0.05 .^{22}$

\section{Ethical considerations}

The Gauteng Department of Education, Ekurhuleni North District, school principals and governing bodies were approached, and gave approval and cooperation for the study. Parents of participants were sent a letter explaining the study details and its nature, and requested to give consent to allow their children to participate in the study. All information was kept confidential.

\section{RESULTS}

The study population consisted of 3764 children from 16 schools; 3468 completed the modified ISAAC questionnaire at the schools (92\% response rate). The study focused only on those children who were present at the time of fieldwork; therefore, 296 learners did not participate. The teachers gave assurance that most of the children were present. School attendance was high during the study, therefore bias, which may have been introduced by non-response rate, was assumed to be relatively low. Forty-four questionnaires were excluded during the data capturing due to incomplete information. A total of 3424 questionnaires were finally included in the data analysis.

Table 1 summarises the frequencies and percentages for general characteristics and living conditions. 53\% of the children were born within the study areas and more than three-quarters had been living in the study areas for longer than 3 years $(76 \%)$. Girls accounted for $52 \%$ of the children.

The majority of the children lived in formal housing structures $(86 \%)$ and fewer than $20 \%$ lived in houses without running water. Ten per cent of the children had a mother or female guardian who was a smoker, $27 \%$ a father or male guardian who was a smoker, or lived with someone who other than their parents, who was a smoker (44\%). Forty-two per cent were exposed to tobacco smoke at home, while 34\% were exposed at school. A small percentage of children reported gas most frequently $(5 \%)$ and paraffin most frequently used $(5 \%)$ for cooking at home, while the majority most frequently used electricity (88\%).

Twelve per cent most frequently used gas for heating, $18 \%$ used paraffin, $7 \%$ used open fires (wood and coal), while the remaining $52 \%$ used electricity. Just over half of the children walked to school $(51 \%)$, while the remainder used other modes of transport (cars, taxi, buses and train). Truck traffic passing near residences almost all day was reported by $35 \%$ of the children. The prevalence of health outcomes is summarised in table 2 . Twenty-one per cent of the children reported having a rash that was coming and going for at least 6 months, the prevalence of ever having a rash in the past 12 months was $17 \%$ and the prevalence of ever having rash in the flexures was $10.2 \%$. EE was reported by $14 \%$ and current ES 9.6\%. ES were more prevalent among girls (table 2).

Table 3 summarises the results of the MLRA for EE set at level 1 for residential areas. After adjusting for potential confounding variables, it was found that the likelihood of EE increased with exposure to: ETS at home (OR $1.3095 \%$ CI 1.01 to 1.67 ) and at school (OR 1.26 $95 \%$ CI 1.00 to 1.60 ). Smoking by mother/female guardian increased the likelihood of EE, however, the association was not significant. Among the confounding variables, significant association was observed for sex, the likelihood of EE was lower for males (OR $0.6695 \%$ CI 0.51 to 0.84), gas frequently used for heating at home (OR 1.76 95\% CI 1.28 to 2.43) and frequency of truck passing near residences on weekdays, frequently throughout the day (OR $1.6095 \%$ CI 1.03 to 2.51 ) and almost all day (OR $1.7095 \%$ CI 1.13 to 2.54). The use of the motor car as mode of transport to school was significant in the univariate analysis, however, it was not significant in the multivariate analysis. No association was observed for age and type of house.

Table 4 summarises the results of the MLRA for current ES. The likelihood of current ES was significantly increased by exposure to ETS at home (OR 1.93 95\% CI 1.43 to 2.59$)$ and school $(1.4495 \%$ CI 1.09 to $1.90)$. Smoking by mother/female guardian increased the likelihood of current ES, however, this was not significant in the multivariate analysis. Among confounding variables, the likelihood of ES was lower for boys (OR $0.5695 \%$ CI 0.42 to 0.76 ). The use of taxi/bus as the mode of transport to school (OR $1.7995 \%$ CI 1.27 to 
Table 1 Demographic characteristics and household conditions of the study participants $(n=3424)$

\section{Variable}

Total Percentage

Age (years)

12

13

14

$\begin{array}{ll}111 & 3.2\end{array}$

$1582 \quad 46.2$

$1731 \quad 50.6$

Sex of child

Female

$\begin{array}{ll}1790 & 52.3\end{array}$

Male

1634

47.7

Residential area

Kempton Park $\quad 1117 \quad 32.6$

Tembisa

$2301 \quad 67.2$

Missing

$\begin{array}{ll}6 & 0.2\end{array}$

Period lived in the residential area

$<6$ months

$253 \quad 7.4$

$6-2$ months

$216 \quad 6.3$

$1-2$ years

$346 \quad 10.1$

$\geq 3$ years

$2609 \quad 76.2$

Born in the areas of Tembisa and Kempton Park

Yes

$1812 \quad 52.9$

No

$1609 \quad 47.0$

Missing

$3 \quad 0.1$

Type of house

Brick

$2938 \quad 85.8$

Mud

$45 \quad 1.3$

$\begin{array}{lll}\text { Corrugated iron } & 184 & 5.5\end{array}$

$\begin{array}{lll}\text { Combination } & 126 & 3.7 \\ & 126 & 3.7\end{array}$

$\begin{array}{lll}\text { Missing } & 126 & 3.7\end{array}$

ETS exposure at residence in the past 30 days

Yes 145242

No $1460 \quad 43$

Missing $\quad 512 \quad 15$

ETS exposure at school in the past 30 days

$\begin{array}{lll}\text { Yes } & 1177 & 34.4\end{array}$

$\begin{array}{lrr}\text { No } & 1452 \quad 42.4\end{array}$

Missing $\quad 755 \quad 23.2$

Residential cooking fuel type most frequently used

Electricity $2995 \quad 87.5$

Gas $\quad 179 \quad 5.2$

Paraffin $\quad 200 \quad 5.8$

Open fires (wood, coal) $\quad 30 \quad 0.9$

$\begin{array}{lll}\text { Missing } & 20 & 0.6\end{array}$

Residential heating fuel type most frequently used

Electricity $\quad 2041 \quad 59.6$

$\begin{array}{lll}\text { Gas } & 426 & 12.4\end{array}$

$\begin{array}{lll}\text { Paraffin } & 631 & 18.4\end{array}$

Open fires (wood, coal) $\quad 270 \quad 7.9$

$\begin{array}{lll}\text { Missing } & 56 & 1.64\end{array}$

Mode of transport to school

Walk

$1728 \quad 50.5$

Informal taxi/Bus $\quad 708 \quad 20.1$

Car $\quad 68320$.

Combination car and informal taxi $201 \quad 5.9$

Train

$100 \quad 2.9$

Missing $4 \quad 0.1$

Frequency of trucks passing near homes on weekdays

Never $\quad 563 \quad 16.4$

Seldom $\quad \begin{array}{rr}1033 & 30.2\end{array}$

$\begin{array}{lrr}\text { Frequently through the day } & 580 & 16.9\end{array}$

Continued
Table 1 Continued

\begin{tabular}{lrr}
\hline Variable & Total & Percentage \\
\hline Almost every day & 1212 & 35.4 \\
Missing & 36 & 1.1 \\
\hline ETS, environmental tobacco smoke. & &
\end{tabular}

2.53) and the frequency of trucks passing near residences almost all day on weekdays (OR 1.95 95\% CI 1.19 to 3.20$)$. No association was observed for the age and type of house. Smoking by participant was not significant in either the univariate or the multivariate analysis, in the stepwise analysis; the inclusion of smoking by participant did not have an effect on the final model and was therefore left out.

\section{DISCUSSION}

The aim of the study was to investigate the association of EE and current ES with ETS among children attending schools in urban areas of Tembisa and Kempton Park, EMM. The prevalence of current ES in this study was $9.6 \%$. In a cross-sectional study of centres participating in the ISAAC, the prevalence of eczema was from $<1 \%$ in Albania to more than $17 \%$ in Nigeria for the age range of 13-14 years. High prevalence of ES was reported in Australia and Northern Europe, and lower prevalences were reported in Eastern and Central Europe, and Asia. Similar patterns were seen for symptoms of severe eczema. ${ }^{9}$ Some centres in Africa were reported to be among those with the highest prevalence of eczema. ${ }^{23}$ In Brazil, Porto Neto reported a prevalence of $13.6 \%$ for eczema in a study conducted among 2948 school children aged 13-14 years following the ISAAC methodology. ${ }^{24}$ The prevalence of current ES in this study is lower than that reported by the study conducted in Polokwane $(17 \%)$ and the two studies conducted in Cape Town, $11.8 \%$ in 1995 and $19.4 \%$ in $2002 .{ }^{12}{ }^{21}$ The slightly lower prevalence for this study might be attributable to the fact that the study area was situated in the Highveld region, with a higher altitude than Polokwane, which is in the Lowveld, while Cape Town is located on the coast.

The study found that EE and ES were positively associated with ETS exposure at home and school. For current ES, the risk of exposure appears to be much higher at home than at school (OR 1.93 at school vs 1.42 at home) as $42 \%$ of the children were exposed to tobacco smoke at home, while $34 \%$ were exposed at school. For ETS at home, the likelihood of ES was much higher in the adjusted model, OR 1.93 versus 1.33.

The findings were in line with other studies that identified ETS as one of the most common indoor air pollutants; the home being the most important site of such exposure. The association between eczema and ETS exposure has been reported previously. ${ }^{25}$ The likelihood of current ES was also associated with smoking by 
Table 2 Self-reported prevalence of eczema symptoms (ES) among boys and girls aged 12-14 years $(n=3424)$

\begin{tabular}{llll}
\hline ES & Total & Females & Males \\
\hline Ever had recurrent itchy rash in the past 6 months & $714(20.9)$ & $418(23.4)$ & $296(18.2)$ \\
Itchy rash in the past year & $575(16.8)$ & $349(74.9)$ & $226(67.3)$ \\
Ever had this rash in flexures & $343(10.2)$ & $224(12.5)$ & $119(7.3)$ \\
Eczema ever & $481(14.1)$ & $289(16.2)$ & $192(11.8)$ \\
Current eczema (ES) & $329(9.6)$ & $214(12.0)$ & $115(7.0)$ \\
\hline
\end{tabular}

mother/female guardian. Yi et $a l^{19}$ found $\mathrm{AD}$ to be highly correlated with ETS among children whose mothers had smoked during pregnancy and/or in the first year after birth, in a study conducted in Korea among 7030 children between 6 and 13 years of age.
In a cross-sectional study conducted among 3153 Lebanese adolescents 13-14 years of age, females and passive smokers were at a 1.5 times risk of having eczema than their counterparts. ${ }^{26}$ An ecological analysis of ISAAC Phase I data from 463801 children aged 1314 years in 155 countries and in 257800 children aged

Table 3 The prevalence of ever having had EE among the participants along with crude and adjusted ORs

\begin{tabular}{|c|c|c|c|c|c|c|}
\hline Variable & Total $^{*}$ & EE (\%) & Crude OR $(95 \% \mathrm{Cl}) \dagger$ & p Value & Adjusted OR (95\% Cl)† & p Value \\
\hline \multicolumn{7}{|l|}{ Age (years) } \\
\hline 12 & 111 & 16.2 & 1 & & 1 & \\
\hline 13 & 1577 & 13.8 & $0.80(0.47$ to 1.36$)$ & 0.430 & 0.88 (0.43 to 1.77$)$ & 0.721 \\
\hline 14 & 1726 & 14.1 & $0.85(0.50$ to 1.44$)$ & 0.561 & $1.09(0.54$ to 2.20$)$ & 0.804 \\
\hline \multicolumn{7}{|c|}{ 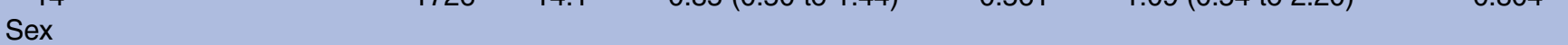 } \\
\hline Female & 1784 & 16.2 & 1 & & 1 & \\
\hline Male & 1630 & 11.8 & $0.69(0.56$ to 0.83$)$ & 0.000 & $0.66(0.51$ to 0.84$)$ & 0.001 \\
\hline \multicolumn{7}{|l|}{ Type of house } \\
\hline Brick & 2928 & 14.11 & 1 & & 1 & \\
\hline Mud & 45 & 15.56 & $1.16(0.51$ to 2.62$)$ & 0.716 & $0.81(0.23$ to 2.75$)$ & 0.738 \\
\hline Corrugated iron & 189 & 15.34 & $1.19(0.78$ to 1.80$)$ & 0.406 & $1.22(0.71$ to 2.12$)$ & 0.459 \\
\hline Combination & 126 & 12.70 & $0.85(0.49$ to 1.45$)$ & 0.560 & $0.74(0.39$ to 1.39$)$ & 0.352 \\
\hline \multicolumn{7}{|c|}{ ETS exposure at home in the past 30 days } \\
\hline No & 1453 & 12.6 & 1 & & 1 & \\
\hline Yes & 1449 & 16.2 & $1.36(1.10$ to 1.68$)$ & 0.003 & $1.30(1.01$ to 1.67$)$ & 0.038 \\
\hline \multicolumn{7}{|c|}{ ETS exposure at school in the past 30 days } \\
\hline No & 1447 & 12.99 & 1 & & 1 & \\
\hline Yes & 1175 & 16.34 & $1.29(1.04$ to 1.61$)$ & 0.019 & $1.26(1.00$ to 1.60$)$ & 0.050 \\
\hline \multicolumn{7}{|c|}{ Mother/female guardian smoke cigarettes } \\
\hline No & 3028 & 13.38 & 1 & & & \\
\hline Yes & 342 & 20.18 & 1.55 (1.16 to 2.08$)$ & 0.003 & $1.18(0.80$ to 1.73$)$ & 0.394 \\
\hline \multicolumn{7}{|c|}{ Fuel frequently used for heating at home } \\
\hline Electricity & 2033 & 12.7 & 1 & & 1 & \\
\hline Gas & 425 & 19.5 & $1.62(1.23$ to 2.13$)$ & 0.001 & $1.76(1.28$ to 2.43$)$ & 0.000 \\
\hline Paraffin & 631 & 14.3 & $1.25(0.95$ to 1.65$)$ & 0.104 & $1.22(0.85$ to 1.75$)$ & 0.273 \\
\hline Open fires & 270 & 16.3 & $1.43(1.01$ to 2.03$)$ & 0.043 & $1.40(0.90$ to 2.18$)$ & 0.127 \\
\hline \multicolumn{7}{|l|}{ Mode of transport to school } \\
\hline Walk & 1723 & 12.71 & 1 & & 1 & \\
\hline Taxi/bus & 705 & 14.18 & $1.13(0.87$ to 1.46$)$ & 0.329 & $1.11(0.80$ to 1.54$)$ & 0.511 \\
\hline Motor car & 683 & 17.13 & $1.42(1.11$ to 1.81$)$ & 0.005 & $1.24(0.84$ to 1.85$)$ & 0.271 \\
\hline Combination & 200 & 14.00 & $1.12(0.73$ to 1.71$)$ & 0.587 & $0.97(0.57$ to 1.68$)$ & 0.930 \\
\hline Train & 99 & 17.17 & $1.44(0.83$ to 2.47$)$ & 0.186 & $1.48(0.77$ to 2.85$)$ & 0.232 \\
\hline \multicolumn{7}{|c|}{ Frequency of trucks passing near homes on weekdays } \\
\hline Never & 562 & 12.28 & 1 & & 1 & \\
\hline Seldom & 1030 & 14.08 & $1.10(0.81$ to 1.51$)$ & 0.519 & $1.21(0.81$ to 1.81$)$ & 0.347 \\
\hline Frequently through the day & 578 & 15.05 & $1.28(0.91$ to 1.08$)$ & 0.151 & $1.60(1.03$ to 2.51$)$ & 0.037 \\
\hline Almost all day & 1208 & 14.57 & $1.27(0.94$ to 1.72$)$ & 0.114 & $1.70(1.13$ to 2.54$)$ & 0.010 \\
\hline
\end{tabular}


Table 4 The prevalence of current ES among the participants along with crude and adjusted ORs

\begin{tabular}{|c|c|c|c|c|c|c|}
\hline Variable & Total $^{*}$ & ES (\%) & Crude OR $(95 \% \mathrm{Cl}) \dagger$ & p Value & Adjusted OR (95\% Cl)† & p Value \\
\hline \multicolumn{7}{|l|}{ Age (years) } \\
\hline 12 & 111 & 16.22 & 1 & & 1 & \\
\hline 13 & 1582 & 10.24 & $0.58(0.34$ to 0.99$)$ & 0.046 & $0.67(0.33$ to 1.38$)$ & 0.289 \\
\hline 14 & 1731 & 8.61 & $0.48(0.28$ to 0.82$)$ & 0.007 & $0.63(0.31$ to 1.30$)$ & 0.219 \\
\hline \multicolumn{7}{|l|}{ Sex } \\
\hline Female & 1790 & 12.0 & 1 & & 1 & \\
\hline Male & 1634 & 7.0 & $0.55(0.43$ to 0.70$)$ & 0.000 & $0.56(0.42$ to 0.76$)$ & 0.000 \\
\hline \multicolumn{7}{|l|}{ Type of house } \\
\hline Brick & 2938 & 9.98 & 1 & & 1 & \\
\hline Mud & 45 & 8.89 & $0.89(0.31$ to 2.50$)$ & 0.829 & $0.62(0.14$ to 2.72$)$ & 0.529 \\
\hline Corrugated iron & 189 & 8.99 & $0.90(0.54$ to 1.50$)$ & 0.699 & $0.67(0.31$ to 1.42$)$ & 0.301 \\
\hline Combination & 126 & 5.56 & $0.53(0.24$ to 1.16$)$ & 0.115 & 0.44 (0.17 to 1.12$)$ & 0.088 \\
\hline \multicolumn{7}{|c|}{ ETS exposure at home in the past 30 days } \\
\hline No & 1460 & 7.5 & 1 & & 1 & \\
\hline Yes & 1452 & 12.4 & $1.73(1.34$ to 2.22$)$ & 0.000 & $1.93(1.43$ to 2.59$)$ & 0.000 \\
\hline \multicolumn{7}{|c|}{ ETS exposure at school in the past 30 days } \\
\hline No & 1452 & 8.6 & 1 & & 1 & \\
\hline Yes & 1177 & 11.6 & $1.40(1.08$ to 1.80$)$ & 0.010 & $1.44(1.09$ to 1.90$)$ & 0.009 \\
\hline \multicolumn{7}{|c|}{ Mother/female guardian smoke cigarettes } \\
\hline No & 3037 & 9.10 & 1 & & 1 & \\
\hline Yes & 343 & 13.12 & 1.48 (1.06 to 2.08$)$ & 0.020 & $1.48(0.97$ to 2.26$)$ & 0.067 \\
\hline \multicolumn{7}{|l|}{ Mode of transport to school } \\
\hline Walk & 1728 & 8.2 & 1 & & 1 & \\
\hline Taxi/bus & 708 & 12.3 & $1.56(1.18$ to 2.08$)$ & 0.002 & 1.79 (1.27 to 2.53$)$ & 0.001 \\
\hline Motor car & 683 & 9.8 & $1.21(0.89$ to 1.65$)$ & 0.207 & $1.12(0.75$ to 1.66$)$ & 0.576 \\
\hline Combination & 201 & 10.5 & $1.31(0.80$ to 2.12$)$ & 0.273 & 1.29 (0.72 to 2.30$)$ & 0.389 \\
\hline Train & 100 & 12.0 & 1.55 (0.83 to 2.92$)$ & 0.166 & 0.94 (0.39 to 2.26$)$ & 0.892 \\
\hline \multicolumn{7}{|c|}{ Frequency of trucks passing near homes on weekdays } \\
\hline Never & 563 & 7.3 & 1 & & 1 & \\
\hline Seldom & 1033 & 9.5 & $1.33(0.91$ to 1.95$)$ & 0.135 & 1.46 (0.89 to 2.41$)$ & 0.132 \\
\hline Frequently through the day & 580 & 9.3 & $1.30(0.85$ to 1.99$)$ & 0.219 & 1.35 (0.77 to 2.36$)$ & 0.293 \\
\hline Almost all day & 1212 & 11.1 & 1.59 (1.10 to 2.29$)$ & 0.012 & $1.95(1.19$ to 3.20$)$ & 0.008 \\
\hline
\end{tabular}

6-7 years in 91 centres in 38 countries, found an association between several factors including smoking by women and the symptom prevalence of three conditions (asthma, rhinoconjunctivitis and eczema). ${ }^{27}$ In South Africa, in the study that was conducted in Polokwane Province, Wichmann $e t a l^{21}$ reported that the likelihood of having ES was significantly increased by $43 \%$ in rural areas and by $54 \%$ when exposed to tobacco smoke at home. The current study was conducted in Gauteng Province, 10 years after the Polokwane study; seemingly, exposure to tobacco smoke is still a problem in different communities in South Africa, with the home still the main environment where children are exposed to tobacco. This study was conducted in an urban setting where the majority of the children lived in formal housing, which may be one of the reasons for the lower prevalence than that in the Polokwane study.

Time spent in the school environment is second to the time children spend at home, and seems to be another area where children are exposed to tobacco smoke.
Children start experimenting with cigarettes while in their early teens and rates of tobacco use among school children aged 13-15 years are high (WHO) ${ }^{28}$ The Global Tobacco Surveillance System Collaborative group has analysed a sample of 747603 adolescents from different countries and continents, and report that the frequency of current tobacco use varies from $11.4 \%$ in the Western Pacific Region to 22.2\% in the Americas, with a global average of $17.3 \%$. In general, girls were reported to smoke less than boys both in the Americas and Europe, while in the leading regions the frequency is almost the same between genders. ${ }^{29}$

In a study conducted in Israel, to investigate the association of smoking and exposure to ETS with prevalence of atopic eczema in a national sample of 10298 children aged 13-14 years, Graif $e t a l^{1}$ reported a dose-response association between smoking and atopic eczema compared to those not smoking. Furthermore, tobacco smoking has been proposed to promote hand eczema; a large population-based study in Sweden reported an 
association between heavy smoking and 1 year prevalence of hand eczema, and a dose-response relation was also indicated..$^{30}$

Conversely, studies such as those by Fedortsiv et $a l^{31}$ Ciaccio et $a l^{32}$ Schafer et $a l,{ }^{33}$ and Strachan and Cook ${ }^{34}$ did not observe any association between atopic eczema and tobacco smoke. The debate as to whether exposure to tobacco smoke is associated with atopic eczema warrants further investigation, as the aetiology of the disease may differ from one country to another due to other risk factors. While research on the matter still continues, policies that are currently available to protect the public and children against exposure to the harmful effects of tobacco smoke should be implemented and enforced. Health education programmes on the harmful effects of tobacco smoke should be strengthened with more resources allocated to such programmes; these should focus on school children.

\section{Limitations of the study}

Certain limitations should be taken into account in the interpretation of the results, which should be interpreted as a whole. First, the study had a cross-sectional epidemiological design, as in all ISAAC studies. Cross-sectional studies are weak in providing causation as they are subject to difficulties in interpreting the temporal sequence of events since health status and determinants are measured simultaneously. However, our findings are supported by other studies, as discussed previously. Second, the results of the study might be higher than the actual prevalence since they are based on selfreported answers from the questionnaire and no allergy testing was performed at the time of data collection.

Third, no quantitative exposure assessment was conducted as part of the study; the number of cigarettes smoked was not included. Fourth, only age, sex, type of house, mode of transport to school, fuel frequently used for cooking and heating at home, and the frequency of trucks passing near residences, were included as confounding variables, of which most were highly significant in the final multilevel model. This supports the hypothesis that the development of eczema is associated with many other factors, therefore, studies on ETS should explore the co-existence of such factors in the development and exacerbation eczema. Despite these limitations, this study will contribute to the existing literature because very little data are available on the prevalence of eczema specifically in Gauteng Province, South Africa. The strength of our study is mainly the use of a validated ISAAC questionnaire, which has been used in many studies globally, with consistent results. Furthermore, cross-sectional studies are important indicators of health problems occurring in communities and serve as a baseline for further analytical and experimental investigation. The study had a large sample size and the participation rate was very high, which eliminated the risk of selection bias.

\section{CONCLUSION}

The study found that eczema was associated with ETS at home and in school. In the literature, most studies investigating eczema in relation to tobacco smoke were cohort studies following children from birth up to the ages of 6-7 years; there are limited studies focusing on the age group of 13-14 years. Studies have also suggested that ETS is associated with increased health symptoms during infancy and that the effect diminishes with the increasing age of the child, however, the results of this study suggest the condition may persist until teenage years through to adulthood. Most epidemiological studies have been conducted in developed countries. The aetiology of the disease may differ from that of children in other parts of the country or children in developed countries. The results of this study will add to the number of limited studies in developed countries, such as South Africa. The baseline data will serve as a benchmark for future epidemiological studies to build more evidence on the effect of ETS on eczema, in order to inform and influence policy decisions and to protect the public against the harmful effects resulting from exposure to tobacco smoke.

Acknowledgements The authors would like to thank all the children who completed the questionnaires, and their parents and school principals. The authors also thank the Gauteng Department of Education for giving permission to conduct the study, the students who conducted the interviews, the data capturers, and Cornelius Nattey and Vusi Nkosi for their assistance during the data processing stages. Finally, the authors would like to thank the University of Pretoria, Tshwane University of Technology, Medical Research Council and the National Research Foundation, for funding the study for academic research purposes.

Contributors JS participated in the design of the study, acquisition of the data, statistical analysis and interpretation of the results, and draft of the manuscript. JW participated in the design of the study, statistical analysis and interpretation of the results, and critically revised the manuscript. KV participated in the design of the study, statistical analysis and interpretation of the results, and critically revised the manuscript. All the authors have read and approved the final manuscript.

Funding Tshwane University of Technology, South Africa; Medical Research Council, South Africa; National Research Foundation, South Africa (grant number TTK20110725000021950).

Competing interests None declared.

Ethics approval The Ethics and Research Committee of the Faculty of Health Sciences, University of Pretoria, approved the study (ethics number: S121 12011).

Provenance and peer review Not commissioned; externally peer reviewed.

Data sharing statement No additional data are available.

Open Access This is an Open Access article distributed in accordance with the Creative Commons Attribution Non Commercial (CC BY-NC 4.0) license, which permits others to distribute, remix, adapt, build upon this work noncommercially, and license their derivative works on different terms, provided the original work is properly cited and the use is non-commercial. See: http:// creativecommons.org/licenses/by-nc/4.0/

\section{REFERENCES}

1. Graif $Y$, German L, Ifrah A, et al. Dose-response association between smoking and atopic eczema: results from a large cross-sectional study in adolescents. Dermatology 2013;226:195-9. 
2. Mohrenschlager M, Ring J. Atopic eczema. Curr Allergy Asthma Rep 2006;6:445-7.

3. Archer BC. Atopic eczema. Medicine 2013;41:6.

4. Johansson SG, Bieber T, Dahl R, et al. Revised nomenclature for allergy for global use: report of the Nomenclature Review Committee of the World Allergy Organization, October 2003. J Allergy Clin Immunol 2004;113:832-6.

5. Matterne U, Schmitt J, Diepgen T, et al. Children and adolescents health-related quality of life in relation to eczema, asthma and hay fever: results from a population-based cross-sectional study. Qual Life Res 2001;20:1295-305.

6. Lewis-Jones S. Quality of life and childhood atopic dermatitis: the misery of living with childhood eczema. Int J Clin Pract 2006;60: 984-92.

7. Su J, Kemp A, Varigos G, et al. Atopic eczema: its impact on the family and financial cost. Arch Dis Child 1997;766:159-62.

8. Carroll C, Balkrishnan R, Feldman S, et al. The burden of atopic dermatitis: impact on the patient, family and society. Pediatr Dermatol 2005;22:192-9.

9. Williams $\mathrm{H}$, Robertson $\mathrm{C}$, Stewart $\mathrm{A}$, et al. Worldwide variations in the prevalence of symptoms of atopic eczema in the International Study of Asthma and Allergies in Childhood. J Allergy Clin Immunol 1999;103(1 Pt 1):125-38.

10. Asher MI, Montefort S, Bjorksten B, et al, the ISAAC Phase Three Study Group. Worldwide time trends in the prevalence of symptoms of asthma, allergic rhinoconjunctivitis, and eczema in childhood: ISAAC Phases One and three repeat multicountry cross-sectional surveys. Lancet 2006;368:733-43.

11. Williams $H$, Stewart $A$, von Mutius $E$, et al, International Study of Asthma and Allergies in Childhood (ISAAC) Phase One and Three Study Groups. Is eczema really on the increase worldwide? J Allergy Clin Immunol 2008;121:947-54.

12. Zar HJ, Ehrlich IR, Workman L, et al. The changing prevalence of asthma, allergic rhinitis and atopic eczema in African adolescents from 1995 to 2002. Pediatr Allergy Immunol 2007;18:560-5.

13. Silverberg IJ, Silverberg BN. Atopic dermatitis: update on pathogenesis and comorbidities. Curr Derm Rep 2012;1:68-178.

14. Suarez-Varela M, Alvarez L, Kogan M, et al. Climate and prevalence of atopic eczema in 6 to 7 year old school children in Spain: ISAAC Phase III. Int J Biometeorol 2008;52:833-40.

15. Ellwood P, Asher M, Bjorksten B, et al., ISAAC Phase One Study Group. Diet and asthma, allergic rhinoconjunctivitis and atopic eczema symptoms prevalence: an ecological analysis of the International Study of Asthma and Allergies in Childhood (ISAAC). Eur Respir J 2001;17:436-43.

16. Smith KR, Mehta S, Maeusezahl-Feuz M. Indoor air pollution from solid fuel use. In: Ezzatti M, Lopez AD, Rodgers A, Murray CJL, eds. Commemorative quantification of health risks: global and regional burden of disease attributable to selected major risk factors. Geneva, Switzerland: World Health Organization, 2004:1435.

17. Chan-Yeung M, Dimich-Ward H. Respiratory health effects of exposure to environmental tobacco smoke. Respirology 2003;8:131-9.
18. Cheraghi M, Salvi S. Environmental tobacco smoke (ETS) and respiratory health in children. Eur J Pediatr 2009;169:897-905.

19. Yi O, Kwon JH, Kim H. Effect of environmental tobacco smoke on atopic dermatitis among children in Korea. Environ Res 2012;113:40-5.

20. Asher MI, Keil U, Anderson HR, et al. International Study of Asthma and Allergies in Childhood (ISAAC): rationale and methods. Eur Respir J 1995;8:483-91.

21. Wichmann J, Wolvaardt J, Maritz C, et al. Association between children's household living conditions and eczema in Polokwane area, South Africa. Health Place 2008;14:323-35.

22. Gortmaker SL, Hosmer DW, Lemeshow S. Applied logistic regression. Contemporary sociology. 2nd edn. New York: John Wiley and Sons, 1994:159.

23. [No authors listed], Worldwide variation in the prevalence of symptoms of asthma, allergic rhinoconjuntivitis, and atopic eczema: ISAAC. The International Study of Asthma and Allergies in Childhood (ISAAC) Steering Committee. Lancet 1998;351: 1225-32.

24. Porto-Neto A, D'Agostini AR, Wolff N, et al. Prevalence and severity of asthma, rhinitis and atopic eczema in 13-14-year-old schoolchildren from Southern Brazil. Allergy Asthma Clin Immunol 2006;2:3-10.

25. Kramer $\mathrm{U}$, Lemmen $\mathrm{C}$, Behrendt $\mathrm{H}$, et al. The effect of environmental tobacco smoke on eczema and allergic sensitisation in children. Br J Dermatol 2004;150:111-18.

26. Al-Sahab B, Atoui M, Musharrafieh U, et al. Epidemiology of eczema among Lebanese adolescents. Int $J$ Public Health 2008;53:60-267.

27. Asher M, Stewart A, Mallol J, et al., ISAAC Phase One Study Group Which population level environmental factors are associated with asthma, rhinoconjunctivitis and eczema? Review of the ecological analysis of ISAAC Phase One. Respir Res 2010;11:8.

28. Page RM Danielson M. Multi-country, cross-national comparison of youth tobacco use: findings from global school-based health surveys. Addict Behav 2011;36:470-8.

29. Warren CW, Riley L, Asma S, et al. Tobacco use by youth: a surveillance report from the Global Youth Tobacco Survey project. Bull World Health Organ 2000;78:868-76.

30. Meding B, Alderling M, Wrangsjo K. Tobacco smoking and hand eczema: a population-based study. Br J Dermatol 2010;163: 752-6.

31. Fedortsiv O, Brozek G, Luchyshyn N, et al. Prevalence of childhood asthma, rhinitis and eczema in the Ternopil region of Ukraineresults of BUPSA study. Adv Med Sci 2012;57:282-9.

32. Ciaccio CE, DiDonna AC, Kennedy K, et al. Association of tobacco smoke exposure and atopic sensitization. Ann Allergy Asthma Immunol 2013;111:387-90.

33. Schafer T, Vieluf $\mathrm{D}$, Behrendt $\mathrm{H}$, et al. Atopic eczema and other manifestations of atopy: results of a study in East and West Germany. Allergy 1996;51:532-9.

34. Strachan D, Cook D. Parental smoking and allergic sensitization in children. Thorax 1998;53:117-23. 


\section{Correction}

Shirinde J, Wichmann J, Voyi K. Environmental tobacco smoke and the risk of eczema symptoms among school children in South Africa: a cross-sectional study. BMJ Open 2015;5:e008234. The first author, Joyce Shirinde, is also affiliated with the School of Health Systems and Public Health, University of Pretoria, Pretoria, South Africa.

BMJ Open 2015;5:e008234corr1. doi:10.1136/bmjopen-2015-008234corr1

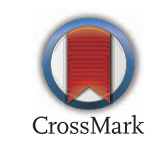

